these will also include contributions on related clinical problems, such as the investigation and treatment of impotence, obesity, and dwarfism. The intention is to provide an up-todate review of some of the more important aspects of this subject.

\section{Staffing in Pathology}

Just before the second world war all the blood counts at one large London teaching hospital were personally carried out by one medical man, now a distinguished professor of haematology. ${ }^{1}$ Today, an average sized district general hospital may get as many as 300 such requests a day, and not only are the scope and complexity of many tests increasing every year but so are the demands for all investigations-an average rise of $12 \%$ every year overall and up to $25 \%$ for specialties such as biochemistry and haematology. ${ }^{2}$

This huge and continuing inorease in the demands on the pathology services has been met in several ways, including the use of automated techniques and the setting up of area laboratories with separate departments in the main specialties staffed by doctors, science graduates, and technicians. But if the content of work in the laboratory is changing, so also are the other demands made on the consultant pathologist. Traditionally, his duties have always included consultation with clinical colleagues about an individual patient, but the growth of medical committees and teaching, whether in medical schools or in postgraduate medical centres, has now imposed considerable further demands on his time outside the laboratory. Thus for a chemical pathology service in the average district hospital a recent report ${ }^{3}$ estimates that three senior staff are needed to cover daily work spent on the following: managerial duties 7 hours; consultation and committee work 3 hours; teaching 1-3 hours, depending on whether medical students are taught; research, development, and scientific meetings 5 hours; annual leave the equivalent of $2 \frac{1}{2}$ hours. The same picture could be painted for other specialties-and in particular the Brodrick report ${ }^{4}$ is likely to increase the work of the morbid anatomy depantment considerably.

Now that the official policy 5 that laboratory services should be centralized in district general hospitals is being put into practice a review of staffing and work load has become urgent. This has been done by a working party of the Royal College of Pathologists, published this month, ${ }^{3}$ which has made far-reaching recommendations. In chemical pathology there should be three senior workers, at least one of whom should be medically qualified. A haematology service, the report suggests, is most efficient and economic when it serves a population of 500,000 and would require a staff of three consultants and four non-medical scientists. For a medical microbiology unit serving 200-300,000 people the staffing should comprise two consultants, together with a senior non-medical scientist, and in histopathology a consultant staff of three or four is required. Finally, the report says that in undergraduate teaching departments all these branches of pathology would require double these numbers of consultants.

Many pathologists in area hospitals will smile wryly at these figures and dismiss the report's suggestions as wishful think- ing. A recent survey has shown how far Britain is still from having even one cunsultant per specialty in every pathology department, ${ }^{2}$ let alone the totals of eleven or twelve per hospital which this report suggests. Last year only $42 \%$ of consultants were found to spend their whole time on a single specialty. ${ }^{6}$ Of 214 chemical pathology departments, 57 had no biochemist or specialist consultant supervision, and only 66 had a specialist consultant in charge. The position was only slightly better in microbiology and haematology.

For all too many hospitals, in fact, the situation is still much the same as that described by "Dr. Alde" in our Unheard Voices series: ${ }^{7}$ without any junior staff, Alde worked with one colleague in a district hospital sharing with him all its work and that of five other hospitals nearby. Yet undoubtedly the Royal College of Pathologists is right to emphasize these ideal levels of staffing if the standards of our pathology departments are to be maintained and improved. Apart from finding enough money to put these recommendations into practice, the main drawback is likely to be a shortage of recruits. The greater ease with which junior staff can now become consultants in one of the clinical specialties, and the increase in the number of vacancies for pathologists in expanding and new departments in the teaching hospitals are likely to make the position more difficult for the peripheral hospital. Yet this would be a tragedy, for, as all clinicians acknowledge, the pathologist plays a vital part in the service to the patient. Any decline in the standards of the laboratory or of the consultation service would be instantly reflected widely throughout the hospital. These latest recommendations should do much to prevent this from happening besides giving the individual consultant pathologist a useful and satisfying career.

1 Pinkerton, J. R. H., Salisbury Medical Bulletin, No. 14, 1972.

2 British Medical fournal, 1971, 3, 719.

3 Staffing and Workload. London, Royal College of Pathologists, 1972 .

4 Home Office, Report of the Committee on Death Certification and Coroners. London, H.M.S.O., 1971. (see B.M.F. 1971, 4, 441.) 5 H.M. (70) 50.

6 Greenbury, C. L., fournal of Clinical Pathology, 1971, 24, 551.

7 British Medical fournal, 1970, 1, 492.

\section{Annual Meeting at Southampton}

The Solent is one of the most attractive areas of England within 100 miles of London, so Southampton has special advantages as the place for the B.M.A. Annual Meeting, which will be held there from 19 to 27 July. Doctors who attend will have the chance of seeing one of the two new medical schools in Britain and, at Winchester, one of the country's oldest seats of learning, where a full day's activities have been arranged by the local division for Sunday 23 July.

The scientific meeting, details of which appear in the provisional programme at p. 25 in the Supplement, will be opened by an address by Sir Thomas Holmes Sellors on the development of thoracic surgery. The programme includes sessions on ageing, prostaglandins and reproduction, breast cancer, ethics and research, the hazards of aquatics, and the injured hand. As usual there is a full programme of social events for doctmrs and their families, and intending visitors are advised to book early. 